\title{
The Importance of Surgical Volume on Outcomes in Thyroid Surgery Revisited: Old is in Again
}

\author{
Editorial Response to “What's Old is New Again” by Julie Ann Sosa \\ (doi: 10.1245/s10434-014-3850-z)
}

\author{
Adam Hauch, MD, MBA ${ }^{1}$, Zaid Al-Qurayshi, MBChB, MPH ${ }^{1}$, Gregory Randolph, MD, FACS ${ }^{2}$, and Emad Kandil, \\ MD, FACS ${ }^{1}$
}

${ }^{1}$ Department of Surgery, Tulane University School of Medicine, New Orleans, LA; ${ }^{2}$ Division of General Otolaryngology, Massachusetts Eye and Ear, Boston, MA

It was with great interest that we read the editorial by Dr. Julie Ann Sosa, "What's Old is New Again," which reviews our recent publication "Total thyroidectomy is associated with increased risk of complications for lowand high-volume surgeons," in the current issue of Annals of Surgical Oncology.

Dr. Sosa has been a pioneer in the field of endocrine surgery and has paved the way for studies examining the relationships between volume and outcomes such as ours.

We agree with Dr. Sosa that the relationship between provider volume and improved patient outcomes is not a novel discovery and has been demonstrated for a number of operations. With regard to thyroid surgery, these relationships have been demonstrated in both pediatric and geriatric thyroid patients. ${ }^{2-6}$

Our study confirms previous findings as Dr. Sosa suggests, and it is currently the largest study of its kind. The fact that it confirms previous findings suggests that such findings are reproducible, and this should not be felt to be an insignificant point. Additionally, using a nationwide database with weighted data points allows us to attempt to scale the data to most accurately reflect information at the national level. By doing so, we confirmed that, nationally, high-volume surgeons performed the smallest percentage of thyroidectomies and not a disproportionately large

(C) Society of Surgical Oncology 2014

First Received: 20 July 2014;

Published Online: 14 August 2014

A. Hauch, MD, MBA

e-mail: ahauch@tulane.edu number, as previously suggested by Sosa et al. ${ }^{2,7}$ However, for the first time using a national database, we show that the type of thyroid operation does have significant influence on morbidity. We demonstrate, by controlling for surgeon volume, and hence, surgeon skills and experience, that these factors are not the sole determinant of complication rates. There is an inherent risk to total thyroidectomy even among high-volume surgeons. This risk, however, is mitigated when high-volume surgeons perform these operations compared with low-volume surgeons, as previously demonstrated. ${ }^{2-6}$

As Dr. Sosa points out, debate currently surrounds the appropriate management for low- and medium-risk differentiated thyroid cancers $<4 \mathrm{~cm}$ in size, and whether thyroid lobectomy or total thyroidectomy should be performed. Additionally, The American Thyroid Association released guidelines in 2009 recommending that thyroid lobectomy alone may be sufficient treatment for isolated indeterminate solitary nodules in those who prefer a more limited surgical procedure and for those with small $(<1 \mathrm{~cm})$, low-risk, unifocal, intrathyroidal papillary carcinomas in the absence of prior head and neck irradiation or radiologically or clinically involved cervical nodal metastases. ${ }^{8}$ These recommendations have been based on data demonstrating similar survival between lobectomy and total thyroidectomy. ${ }^{9-11}$

Despite these recommendations, there has been an increasing trend toward performing total thyroidectomy, especially for the management of benign disease, in America over the last 15 years, and total thyroidectomy continues to be offered for cases of microcarcinoma and low-grade thyroid malignancies. ${ }^{12-16}$ 
Notwithstanding some of the limitations of this study, it hopefully portrays, using a large national database, that the type of thyroid resection does have significant influence on short-term morbidity, and hence, surgeon skills and experience are not the sole determinant of surgical outcomes. Rather, there is an inherently higher risk when offering total thyroidectomy that persists across surgeon volumes. As such, all surgeons, regardless of experience, should by mindful of the intrinsic risk when considering performing total thyroidectomy in patients. Additionally, as debate continues around the management of low-risk thyroid cancers and microcarcinomas, we hope that our study will play an important role in influencing future recommendations. We shall wait to see as these recommendations unfold.

\section{REFERENCES}

1. Hauch A, Al-Qurayshi Z, Randolph G. Total thyroidectomy is associated with increased risk of complications for low- and highvolume surgeons. Ann Surg Oncol. doi:10.1245/s10434-0143846-8.

2. Sosa JA, Bowman HM, Tielsch JM, Powe NR, Gordon TA, Udelsman R. The importance of surgeon experience for clinical and economic outcomes from thyroidectomy. Ann Surg. 1998;228:320-30.

3. Loyo M, Tufano RP, Gourin CG. National trends in thyroid surgery and the effect of volume on short-term outcomes. Laryngoscope. 2013; 123:2056-63.

4. Gourin CG, Tufano RP, Forastiere AA, Koch WM, Pawlik TP, Bristow RE. Volume-based trends in thyroid surgery. Arch Otolaryngol Head Neck Surg. 2010;136:1191-8.

5. Cherenfant J, Gage M, Mangold K, Du H, Moo-Young T, Winchester DJ, et al. Trends in thyroid surgery in Illinois. Surgery. 2013;154:1016-23.
6. Kandil E, Noureldine SI, Abbas A, Tufano RP. The impact of surgical volume on patient outcomes following thyroid surgery. Surgery. 2013;154:1346-52.

7. Sosa JA, Mehta P, Wang TS, Boudourakis L, Roman SA. A population based study of outcomes from thyroidectomy in aging Americans: At what cost? J Am Coll Surg. 2008;206:1097-105.

8. American Thyroid Association (ATA) Guidelines Taskforce on Thyroid Nodules and Differentiated Thyroid Cancer, Cooper DS, Doherty GM, Haugen BR, Kloos RT, Lee SL, et al. Revised American Thyroid Association management guidelines for patients with thyroid nodules and differentiated thyroid cancer. Thyroid. 2009;19:1167-214.

9. Mendelsohn AH, Elashoff DA, Abemayor E, St John MA. Surgery for papillary thyroid carcinoma: Is lobectomy enough? Arch Otolaryngol Head Neck Surg. 2010;136:1055-61.

10. Haigh PI, Urbach DR, Rotstein LE. Extent of thyroidectomy is not a major determinant of survival in low-or high-risk of papillary thyroid cancer. Ann Surg Oncol. 2005;12:81-9.

11. Nixon IJ, Ganley I, Patel SG, Palmer FL, Whitcher MM, Tuttle RM, et al. Thyroid lobectomy for treatment of well differentiated intrathyroid malignancy. Surgery. 2012;151:571-9.

12. Ho TW, Shaheen AA, Dixon E, Harvey A. Utilization of thyroidectomy for benign disease in the United States: a 15-year population-based study. Am J Surg. 2011;201:570-4.

13. Loyo M, Tufano RP, Gourin CG. National trends in thyroid surgery and the effect of volume on short-term outcomes. Laryngoscope. 2013;123:2056-63.

14. Hay ID, Hutchinson ME, Gonzalez-Losada T, McIver B, Reinalda ME, Grant CS, et al. Papillary thyroid microcarcinoma: A study of 900 cases observed in a 60-year period. Surgery. 2008;144:980-7.

15. Lin HW, Bhattacharyya N. Survival impact of treatment options for papillary microcarcinoma of the thyroid. Laryngoscope. 2009;119:1983-7.

16. Baudin E, Travagli JP, Ropers J, Mancusi F, Bruno-Bossio G, Caillou B, et al. Microcarcinoma of the thyroid gland: the Gustave-Roussy Institute experience. Cancer. 1998;83:553-9. 